\title{
Invisible Lives and Hidden Realities of Undocumented Youth
}

\author{
FARIA KAMAL AND KYLE D. KILLIAN
}

\begin{abstract}
This qualitative study explored the lived experiences of undocumented youth and the mental health impacts of living in daily fear of detention and deportation. In-depth, semi-structured interviews were conducted to examine the repercussions of living without immigration status, and the descriptive data were analyzed using a grounded theory approach. Results indicate that lack of immigration status is associated with mental health issues, particularly anxiety. Absence of immigration status is implicated as a decisive social factor influencing individuals' mental and social well-being.
\end{abstract}

\section{Résumé}

Cette étude qualitative portait sur les expériences vécues des jeunes personnes sans papiers et les impacts en matière de santé mentale de vivre quotidiennement dans la peur d'être détenu ou déporté. Des entrevues en profondeur semi-structurées étaient effectuées afin d'examiner les répercussions de vivre sans statut d'immigrant, et les données descriptives étaient analysées selon une théorie à base empirique. Les résultats indiquent que l'absence de statut d'immigrant est associée à des problématiques de santé mentale, surtout l'anxiété. Le fait de ne pas avoir un statut d'immigrant est donc considéré comme un facteur social décisif qui influe sur le bien-être mental et social des individus.

\section{Introduction}

I mmigration status, or lack thereof, is an important determinant of mental health and social well-being. ${ }^{1}$ Undocumented or non-status immigrants live in
Canada without full, permanent legal immigration status, such as individuals who have fallen completely out of status without recourse and individuals obtaining temporary work permits, student permits, permanent residency, or humanitarian and compassionate permits, but who do not have status, despite being formally engaged with the immigration and refugee system. Non-status persons confront a wide range of mental health issues, but as the result of restrictive public policies are rarely accorded the opportunity to access health care, education, and myriad other vital social services. ${ }^{2}$ Although the terms undocumented and non-status are used interchangeably in research to reference the same population, this article will use the term undocumented for the sake of consistency.

In Canada, conservative estimates hold that there are more than 500,000 undocumented immigrants, over 80,000 of whom reside within the Greater Toronto Area. ${ }^{3}$ Because the size of this population is so very large, it is imperative to explore the mental health concerns that may arise from living in daily fear of detention and deportation in an attempt to better formulate public health policies that address the needs of undocumented residents. Given that studies on undocumented adolescents have rarely been conducted in Canada, this study aimed to help bridge the gaps in literature and knowledge on how lack of immigration status affects youth. In particular, this study investigated what it means to be undocumented and how living without legal immigration status informs undocumented youths' sense of identity, general mental health, and social integration.

\section{Review of the Literature}

Scant literature explores the lives of undocumented residents in Canada and most countries of the Global North, which have, in recent decades, become home to significant numbers of undocumented migrants. ${ }^{4}$ This lack of research 
is attributed largely to the fact that undocumented migrants actively and quite consciously remain hidden from public view in order to avoid detection and deportation. 5 Although the inability of most researchers to access such populations remains the most pronounced reason that there are only the scantiest research data, several other factors may deter studies of undocumented residents. Historically, governments in the Global North, and their respective research institutions (including public universities), have been highly critical of funding any research projects involving "illegal" populations, whose presence within the host country is often denied outright or ignored by the government. ${ }^{6}$ Investigators from various disciplines contend that the lack of funds available for this research is politically motivated because the state, along with multinational corporations, has an invested economic interest in ensuring that undocumented populations remain outside the ambit of conventional scientific inquiry because such scrutiny could reflect poorly on state policy and ideologies.7 Such proponents further assert that government commissions such as the United States Select Commission on Immigration and Refugee Policy make erroneous statements about the nature of this population and why research with such populations is unfeasible and, ultimately, not eligible for government funding. ${ }^{8}$ For example, the U.S. Commission on Immigration and Refugee Policy made a public declaration against fieldwork with undocumented migrants, stating that the impacts of "illegal immigrants are basically unknown and unknowable" and thus research of this population would not be funded. 9 This, coupled with the fact that there is no way to have a strict randomized sample on a large clandestine population, makes fieldwork in the area particularly complex, time-consuming and challenging. Despite such obstacles, researchers have conducted research with this population, which will be reviewed below.

\section{Brief Overview of How People Become Undocumented}

Contrary to popular discourse, which paints undocumented peoples as covertly entering Canada through illicit or illegal means, almost all undocumented peoples enter Canada with some kind of legal status, including work permits and visas. ${ }^{10}$ However, they are often unable to live with status after these permits and visas expire, as Canada's immigration system systematically privileges specific types of immigrants over others, prioritizing well-educated, upper-middle class individuals. ${ }^{11}$ As a result, those individuals entering Canada through temporary work programs in service and labour industries or through travel visas are unable to garner enough points to qualify under Canada's Immigration Point System. ${ }^{12}$ Furthermore, refugees claimants are systematically denied status since over half are outright denied. ${ }^{13}$ Consequently, many individuals, after being denied legal status, make the difficult choice to stay in Canada as an undocumented migrant. Since the focus of this paper is on adolescents, it is necessary to make salient the fact that although adult immigrants choose to relocate to Canada for myriad economic and political reasons, children and youth do not have the same choice, as they usually immigrate because their parents have made the decision on their behalf. As such, youth do not possess the same level of autonomy and agency as their adult counterparts in decisions regarding migration.

\section{General Health of Undocumented Immigrants}

Congruent with research on other marginalized groups in society, undocumented immigrants have numerous health needs that are not met, especially mental health services, which are rarely, if ever, offered. ${ }^{14}$ Moreover, their needs are frequently ignored by mainstream health professionals, most of whom are not trained to respond to such concerns or are ill-equipped to do so, restricted by financial and institutional barriers. ${ }^{15}$ In general, health security-referring to the concept of personal safety, protection from health risks, and ability to access health care in a timely manner-for undocumented residents tends to be extremely precarious. ${ }^{16}$ This void is largely the result of public policies that excise undocumented peoples from accessing municipal, provincial, or federal resources, as access is directly contingent upon having legal status. ${ }^{17}$

Consequently, undocumented residents have higher rates of illness and hospitalization because their lack of health insurance coverage prevents them from receiving care when smaller health concerns arise. ${ }^{18}$ Furthermore, undocumented immigrants have higher incidences of being hospitalized for more serious, life-threatening concerns than conventional immigrants with legal status. ${ }^{19}$ This disparity is attributed to the fact that undocumented peoples are reticent to access vital services, such as health care, for fear of detention and deportation. ${ }^{20}$ In addition, health-care costs are a serious deterrent, since undocumented migrants are expected to pay out of pocket for all services. ${ }^{21}$ Another reason undocumented residents are unable to access health services and have higher rates of hospitalizations is the paucity of health providers who serve such populations. ${ }^{22}$ In addition, many undocumented immigrants face linguistic and cultural barriers that further deter them from accessing services. ${ }^{23}$

Undocumented children and youth, in particular, bear the brunt of this lack of health security, since they are rarely afforded the opportunity to receive treatment for any illness, minor or major. Children born to undocumented parents receive negligible prenatal and postnatal care, suffer from higher incidences of health problems in infancy, and are 
less likely to receive medical treatment than those born to immigrant parents with legal status. ${ }^{24}$ Although children of undocumented parents born in Canada are Canadian citizens and therefore endowed with all the rights that come with such a title, they are less likely to access health care because their parents fear that taking their child to a medical facility may expose their lack of immigration status and result in deportation. ${ }^{25}$ Additionally, youth who reside in Canada without formal legal status, similar to their parents, are unable to receive treatment or annual checkups, which are common for other children their age, and rarely visit a doctor, even in times of need. ${ }^{26}$ Given that undocumented families are encumbered with exorbitant financial costs when accessing health care, coupled with the palpable threat of detention or deportation when accessing services, undocumented youth lack meaningful health security in Canada.

\section{Employment and Financial Stressors}

For most individuals in society, financial and economic security is the direct corollary of procuring steady, well paid employment. This type of security is usually found within primary markets, which employ salaried professionals in the government or private sector who engage in nonmanual labour. ${ }^{27}$ Although undocumented immigrants participate in the workforce at higher rates than both legal immigrants and the general population, they are relegated to working permanently within the informal economy because they are unable to obtain employment in primary markets, since they do not have legal work authorization. ${ }^{28}$ The informal economy, as described by Portes, refers to the "sum total of income-earning activities that are unregulated by legal codes in an environment where similar activities are regulated. Informal activities are distinguished from criminal ones in that they encompass goods and services that are legal, but whose production and marketing is unregulated. ${ }^{29}$

Work within the informal economy is precarious, as there are no labour or environmental laws governing any practices, nor are there any benefits for workers, and as a result, exploitation is deeply ensconced within such industries.

Sectors with significant concentrations of undocumented workers include construction, agriculture, manufacturing, hotel, and service industries. $3^{\circ}$ Such "under-the-table" wages are woefully insufficient for most individuals' and families' subsistence, and as a result, undocumented immigrants are the working poor, who maintain steady employment but whose wages total less than the poverty level of the host nation..$^{3}$ Many undocumented youth enter the workforce to support their families and pay for education. ${ }^{32}$ Like their parents, they are permanently relegated to low-wage jobs within the informal economy. The nature of working within the informal economy subjects adults and adolescents alike to greater health and safety risks because these settings are unregulated. ${ }^{33}$ Consequently, compromised physical health status and mental stress due to job-related risks are highly prevalent in undocumented populations. ${ }^{34}$ Although living without legal immigration status is itself implicated with significantly higher levels of stress in youth and adults, constant financial insecurity negatively affects undocumented youths' morale, sense of wellness, beliefs about the future, and sense of hope. ${ }^{35}$ Youth and adolescents express a sense of general malaise when confronted with the grim reality that their only option for obtaining employment is in the informal economy and that this may remain their reality indefinitely, or at least until they procure legal status. ${ }^{36}$ Undergoing development in conditions where professional growth and related identity is severely constrained because of lack of documentation creates conditions conducive to hopelessness, depression, powerlessness, anxiety, and higher levels of stress. ${ }^{37}$ In other words, when employment and financial factors impel undocumented youth and adolescents to work in precarious jobs, and they feel there is no upward mobility because of a lack of status, their development may be truncated and their mental health negatively affected.

\section{Emotional Impact of Fear of Detention and Deportation}

\section{Social Impairment}

Social impairment refers to difficulties initiating and maintaining satisfying relationships and tends to affect functioning. ${ }^{3}$ Such difficulties in relationships may be manifested through avoidance, irritability, and conflict with parents, siblings, or peers. 39 Undocumented youth often consciously avoid interacting with peers and initiating close friendships or relationships out of fear that others may find out and disclose their status. ${ }^{40}$ Such avoidance is not rooted in simple puerile insecurity or pathological complexes, but reflects youths' understanding of their social surroundings and the belief that disclosure of status would negatively impinge upon both their life and the lives of family members. ${ }^{41}$ Thus, lack of trust in relationships is more closely related to not having status and concomitant fears. This is of concern, given the fact that the ability to form and maintain stable friendships and forge romantic partnerships is typically witnessed in normally developing adolescents, and lack of trust-despite being unrelated to pathological complexes-may impede normal development in undocumented adolescents, since there are palpable disincentives to reveal personal information about oneself and form close ties with peers or romantic partners. ${ }^{42}$ 
Many undocumented youths' patterns of conflict with their family members are borne out of a sense of exasperation, discontentment, and futility in changing their status. ${ }^{43}$ Although adolescence is normally a period where parentchild relationships witness more intense confrontations and conflict, such strife is typically a function of the adolescent's growing cognitive and social abilities whereby their desire for greater freedoms causes friction with parents, undocumented youths' conflict with their parents are oftentimes associated with their lack of status and the ways in which immigration status itself restricts their personal freedom to obtain a driver's licence, gain legal employment, participate in extra-curricular activities, or frequent public spaces such as malls and movie theatres where security personnel and police are present, without fear or threat of detention and deportation. Such parent-child tensions often remain unresolved, as parents are unable to grant such freedoms on an individual level to their children, leaving such tensions and conflicts unresolved and an environment where frustration and futility may easily emerge.

Examining developmental patterns among undocumented youth shows atypical problems in developing and maintaining friendships and romantic partnerships, along with atypical problems in the parent-teen relationship, which typify social impairment. Although there is a relationship between social impairment and psychological disorder, these symptoms are not necessarily acute enough to warrant a diagnosis but are important stressors nonetheless. ${ }^{44}$

\section{Loneliness and Depression}

Undocumented youth often express a profound sense of loneliness, which stems from their belief that other youth simply do not understand what it means to live without immigration status and therefore feel that many of their relationships are characterized by lack of understanding and empathy. ${ }^{45}$ Consequently, many undocumented youth feel they are struggling alone. ${ }^{46}$ Such sentiments are further exacerbated by feelings of powerlessness and hopelessness, which are related to the lack of opportunity and understanding that they do not possess the agency required to alter their status. Such beliefs, thoughts, and emotions give rise to depression in undocumented youth populations. ${ }^{47}$ Furthermore, it is commonplace for such youth to yearn for privileges denied them because of their lack of status. ${ }^{8}$ Most research in the field has chronicled how youth constantly desire a driver's licences, student visa, and work authorization. When such aspirations go unrealized, many youth become depressed that they are unable to engage in age-appropriate activities and feel left out. 49 Thus, loneliness and depression are recurrent themes in the lives of undocumented youth.

\section{Anxiety}

While living without status, many undocumented youth experience extended periods of anxiety and feel apprehensive about their unstable future. ${ }^{50}$ Incapable of predicting where they will be residing in a year (due to threat of deportation), youth experience high levels of anxiety, especially when planning education and employment..$^{11}$ In particular, undocumented youth experience a variant of "persecutory anxiety," which results in an emotional state "whereby the host environment ... is experienced as hostile and persecutory" because of the threat and fear of imminent or distant deportation. ${ }^{52}$ Such anxiety is endemic to undocumented youth because they must contend daily with deportationrelated distress.

Almost all of the literature examining impacts of lack of immigration status on youth have been conducted in the United States and it is important to note that even there, such studies are few and far in between. This study seeks to investigate such impacts in Canada and investigate the ways in which adolescents are affected by their lack of immigration status. Because adolescence is a period of rapid cognitive, social, and emotional growth, in which identity is developed and consolidated, it is necessary to study whether undocumented youth exhibit atypical developmental patterns, as this would have significant mental health impacts on the family and individual unit as well as have implications for social and health policies. Further, this study specifically aims to examine the ways in which status affects stress, anxiety, loneliness, and general health security.

\section{Methods}

Qualitative designs are appropriate for exploring the lived realities of populations from their own distinct perspectives. ${ }^{53}$ As little research has been conducted in Canada on the mental well-being of undocumented youth, this study functions as a preliminary exploration of the ramifications of living in daily fear of detention and deportation. As such, a qualitative approach was adopted to accurately gauge what factors affected youths' and young adults' sense of mental well-being. It should be noted that non-status youth represent a particularly vulnerable population, and protecting confidentiality is a matter of personal safety and security. To ensure this, the researcher secured Research and Ethics Board approval at the university level and ethics approval at each of the social service organizations where recruitment took place, and all clearances were garnered with the understanding that names and addresses would not be collected at any stage of the research. For participants under 15 years of age, verbal consent was attained from parents. 
Sample

To gain access to this population, community partnerships were forged between the researcher and three social service organizations in the Greater Toronto Area that work closely with undocumented youth. ${ }^{54}$ Although all three organizations service undocumented youth, none maintain formal statistics on services provided to this population. Since a strict randomized sample was not possible to find, a convenience sample was obtained through these three organizations. A sample of 47 undocumented youth was ultimately selected who resided in Canada without status anytime between the ages of 13-22, and were currently within the (same) age bracket of 13-22. Youth participating in the study varied in length of time they were undocumented, ranging from 11 months to 14 years. In an attempt to establish gender parity and explore whether there were any differences based on sex, 24 males and 23 females were selected (see table 1 for a summary of the sample's demographic characteristics).

\section{Recruitment}

Recruitment for this study was conducted by each of the three organizations internally, as they were privy to immigration information about their respective clients and had provided institutional ethical clearance for the study. On the basis of participant requirements set by the researcher whereby all individuals had to be 13-22 years of age and living without immigration status, each organization designated a staff member to select participants that fit these criteria. Each organization selected 15-20 individuals and provided the researcher with their contact information when the individual agreed to be part of the research and consented to being contacted by the researcher. Afterwards, the researcher contacted the participant individually and set up a time and location to conduct the interview.

\section{Procedure}

In-depth, semi-structured interviews were conducted by asking nine open-ended questions followed by questions that provided opportunities for participants to elaborate on their responses (see table 2 for the list of interview questions). For example, follow-up questions were asked when the interviewer felt the participant had not answered a question fully or when the participant raised issues that seemed relevant to the study. All interviews took place in individual sessions that ranged from one and a half to two hours in length. All interviews were digitally recorded with the permission of the participants and transcribed verbatim afterwards. The descriptive data were analyzed using a grounded theory approach. Through a method of constant comparison, recurring topics, keywords, and phrases within and across the interviews, coding categories
Table 1. Demographic characteristics of the sample

\begin{tabular}{|c|c|}
\hline Demographic variables & Number of participants \\
\hline \multicolumn{2}{|l|}{ Age } \\
\hline 13 & 1 \\
\hline 14 & 1 \\
\hline 15 & 12 \\
\hline 16 & 10 \\
\hline 17 & 13 \\
\hline 18 & 7 \\
\hline 19 & 1 \\
\hline 20 & 1 \\
\hline 21 & o \\
\hline 22 & 1 \\
\hline \multicolumn{2}{|l|}{ Gender distribution } \\
\hline Male & 24 \\
\hline Female & 23 \\
\hline \multicolumn{2}{|l|}{ Country of origin } \\
\hline Mexico & 16 \\
\hline Jamaica & 10 \\
\hline Philippines & 7 \\
\hline Sri Lanka & 5 \\
\hline Nicaragua & 4 \\
\hline Bangladesh & 2 \\
\hline Haiti & 2 \\
\hline Costa Rica & 1 \\
\hline \multicolumn{2}{|l|}{ Duration of stay in Canada } \\
\hline $0-2$ yrs & 9 \\
\hline $2-4$ yrs & 15 \\
\hline $4-6$ yrs & 19 \\
\hline $6-8 \mathrm{yrs}$ & 2 \\
\hline $8+y r s$ & 2 \\
\hline \multicolumn{2}{|l|}{ Work status } \\
\hline Working & 39 \\
\hline Not working & 8 \\
\hline \multicolumn{2}{|l|}{ Family income } \\
\hline$<10 \mathrm{~K}$ & 11 \\
\hline $10 \mathrm{~K}-19 \mathrm{~K}$ & 14 \\
\hline $20 \mathrm{~K}-29 \mathrm{~K}$ & 22 \\
\hline \multicolumn{2}{|l|}{ Education completed } \\
\hline Middle school & 47 \\
\hline High school & 4 \\
\hline \multicolumn{2}{|c|}{ English proficiency (self-reported) } \\
\hline Good & 45 \\
\hline Fair & 2 \\
\hline Poor & o \\
\hline
\end{tabular}


Table 2. Interview questions

\begin{tabular}{ll}
\hline 1 & How would you describe yourself? \\
2 & What do you identify yourself as? How did you identify yourself before you moved to Canada and how would you identify yourself today? \\
3 & Does your immigration status - or lack thereof-affect you? Your family? Your community? \\
5 & What are your sources of motivation and support? (Examine familial, peer, and institutional levels.) \\
6 & What are the biggest stressors in your life? How do they make you feel? \\
7 & What could be done to alleviate the stress you feel? \\
8 & What do you immediately associate with the words detention and deportation? \\
9 & What do you see as the biggest hurdle to gaining full immigration status? How do you tackle this issue?
\end{tabular}

and relationships among the data sources were mapped out through repeated sifting of the data. ${ }^{55}$ Subsequent stages of focused coding involved renaming and condensing codes and use of "family" or umbrella categories that brought together the underlying codes they represent. The codes and themes that emerged from the participants' narratives were analyzed by examining the participants' social location on the contextual variable of immigration status and how this location informed their experiences.

\section{Results}

Several themes were mentioned by all or almost all participants (see table 3 for prevalence of coded factors). All study participants reported experiencing emotional and psychological distress, including chronic stress, depression, loneliness, trauma, anxiety, hopelessness, and social impairment related to lack of immigration status. Although participants expressed these issues in different ways and to varying degrees, such themes were consistent across all 47 participants, irrespective of sex, age, education, ethnicity, and all other demographic variables. Distress was expressed within the participants' narratives as stemming from living in constant fear of deportation or detention and lack of individual control over the future and their own lives. Throughout the duration of the study, it was made salient that beyond the individual impacts on youth, the greatest impact of health security, or severe lack thereof, was on the family unit. Participants indicated that many family members suffered from similar symptoms and distress to those experienced by the youth in the study.

\section{Impact of Living without Status on Youth Identity Formation and Consolidation}

Adolescence is a time of intensive social and personal development, one in which identity development and consolidation take centre stage, making it imperative to examine the effects of living without status on youth personal identity. ${ }^{56}$ In general terms, personal identity refers to an individual's mental representation of his or her own social, emotional, and cognitive characteristics and is best understood as a complex bio-psychosocial phenomenon, meaning that biological, psychological, and social/environmental factors are all implicated in identity creation and formation. ${ }^{57}$ Undocumented youth develop within a social environment where their very presence is viewed as threatening (and thus, subject to detention and deportation), which has shown to interfere with conventional processes and mechanisms of identity formation in adolescence. Three themes were identified as negatively affecting undocumented youths' sense of identity: invisibility, consciousness of criminality, and undocumented consciousness.

\section{Invisibility}

One of the most frequent themes related to not being able to form a cohesive self-identity was that of invisibility-thoughts and feelings related to the belief that an individual's presence within the physical confines of a state is consciously ignored and erased. Invisibility impeded formulating a sense of self because participants believed that their very existence was socially and systematically invalidated, thus making it difficult to form an identity, given that societal institutions failed to even acknowledge their existence. As Participant A reported,

It's like, I don't even exist in Canada. If I don't exist then how can I be here talking to you, you know? It doesn't make sense to me ... I'm trying to figure out all this noise in my head but if I don't exist, then, does it even matter?

Another participant further elucidated,

The other day we had to do this assignment at school about what our interests are, what we want to become, what kind of person we are, all those type of stuff. Anyway, I'm doing this assignment ... and I'm thinking that it's all good to know this, but it doesn't matter for me. I can't take advantage of this knowledge [about myself] 
Table 3. Prevalence of coded factors

\begin{tabular}{|c|c|c|}
\hline Primary category & Factors & $\begin{array}{r}\text { Number of } \\
\text { participants }\end{array}$ \\
\hline \multicolumn{3}{|l|}{ Identity formation/ } \\
\hline \multirow[t]{6}{*}{ consolidation } & & 47 \\
\hline & Invisibility & 41 \\
\hline & Consciousness of & \\
\hline & criminality & 36 \\
\hline & Undocumented & \\
\hline & consciousness & 47 \\
\hline \multirow[t]{11}{*}{ Stress and anxiety } & & 47 \\
\hline & Inability to control & \\
\hline & future & 46 \\
\hline & Fear of disclosure & \\
\hline & of immigration & \\
\hline & status & 47 \\
\hline & Inability to access & \\
\hline & vital services & 39 \\
\hline & Employment and & \\
\hline & financial stressors & 47 \\
\hline & Lack of information & 44 \\
\hline \multirow[t]{3}{*}{ Protective factors } & & 42 \\
\hline & Familial support & 38 \\
\hline & Sense of agency & 37 \\
\hline
\end{tabular}

because even after I figure out all this stuff, like what I want to do or interests or who I am-whatever that means-it's not like I'm going to get the chance to apply it. In the end, I can't get a job that represents who I am ... [because] I apparently don't exist in Canada ... it doesn't matter who I think I am or all that, the only thing in the end that really matters is if I have status or not ... and no amount of getting to know myself or filling out questionnaires during Civics class that are supposed to tell me about myself matters if you ain't got no status.

Thus, feelings of invisibility cause youth to view processes of development as being somewhat inconsequential when faced with structural and societal constraints that are the immediate corollary to living without status.

Furthermore, feeling of being made invisible is associated with social exclusion, which negatively affects youths' identity. Participant F conveys such sentiments with clarity:

My family came here [to Canada] years ago and I always hear all this talk about how this country's so multicultural and blah blah blah ... how Canada isn't, like, as racist as the U.S. That's not the Canada I live in. For seven years I've been living without status, and for seven years I feel like I don't belong ... like other people don't want me here ... that I'm not wanted. I used to feel really sad [about this] ... like an outsider in my own home ... I don't know, but sometimes I feel coming here and living without status raped me ... it raped me of my dignity, it raped me of my self-respect, it raped me of my rights ... it raped me of me.

From such vignettes, it is notable that undocumented youths' feelings of exclusion and marginalization within Canadian society impedes development of identity and leads to experiences in which their sense of identity is negated by their precarious immigration status. In other words, and as expressed by all 47 participants, identity formation and issues surrounding who they are are as individuals is directly informed by what they are in Canada: individuals made invisible who live as "second-class, maybe no class, people without rights," as stated by another participant. Thus, lack of immigration status impedes development of a coherent self-identity because of the constant precariousness of being undocumented and made invisible. This is particularly noteworthy, as feelings of invisibility are associated with distress, frustration, and depression in refugee populations, which may lead to disturbances in forming a coherent self-identity, since typical development does not include extended periods of depression and clinical distress. ${ }^{5}$ Feelings of invisibility increased with the length of time during which the individual lived in Canada without status. Those who resided without status for more than two years mentioned feelings of invisibility with greater frequency in their narratives than those who had been living without status for less than two years. However, this finding should be interpreted with caution, as feelings of invisibility may have been more frequently mentioned by participants not just as a function of duration of time living without status, but may also be due to age and awareness that is a corollary of development and more defined awareness about such issues.

\section{Consciousness of Criminality and Undocumented Consciousness}

Living within a country where the discourse about immigration, especially about immigrants without formal legal status, is often exclusionary and hostile, and creates an environment conducive to fear and insecurity. For undocumented immigrants, the very language surrounding their lives elides their presence within the host nation and is suffused with pejorative terms, such as illegal alien, parasite, wetback, and criminal, among others. Thus, growing up in such a social environment may make creating a secure sense of self-identity-one of the milestones of development in adolescence-challenging and fraught with difficulty. In particular, the "consciousness of criminality," referring to the stigma undocumented youth experience because they 
live in Canada "illegally" and are denigrated, results in a denuded sense of self and negative feelings about identity.

This "consciousness of criminality" is disseminated most potently through media production and reproduction of undocumented individuals as criminals. These types of depictions affect undocumented youths' sense of identity because they are consistently exposed to such stories through television programs, news, articles, and other publications. Because they are portrayed as criminals, 36 of the 47 participants reported feelings of discomfort, stress and tension when asked about how their identity was affected by such media images. Participant D stated,

I hate how the media and these politicians make us to be. They always flash these crazy stories about illegal [immigrants] committing crimes and doing bad things and yeah, I know, some do, but they make us to be, like, that, we're all like that. The only time I ever see people like me on TV ... [is] when we're doing something wrong or [when] some newsperson ... is telling [viewers] how we're bad people ... and it gets to you sometimes. I know it's not true, but [it] still gets to me. It's 'cuz I know if I ever do anything, it won't be like [name omitted] did something bad, it's gonna be ... all these illegal immigrants are bad. So I feel [I] gotta be good so I don't mess it up for everyone else [who is in my situation].

Thus, when undocumented youth are forming their sense of identity, they are aware of the social milieu in which their development occurs and feel that they must conform and be the "good child" or "good citizen" in order to be accepted within society as an undocumented individual.

Further, this pressure to conform affects their identity because they are keenly aware that they are defined by their lack of immigration status before they are ever defined as an individual, which is referred to as the "undocumented consciousness." As one participant put it,

To be straight up, I don't think it matters [who I am] ... [because] they (society) don't care. When I go somewhere or do something, the first thing you need is proof of who you are ... like a health card or driver's licence. So it doesn't matter how nice I am ... if I treat people good, if I'm a good student ... people just see you as illegal if you don't have [legal immigration] papers.

Another participant also stated,

I'm not trying to say that personality and stuff and [who] you are doesn't matter at all or anything. I need to sleep at night and I wanna know that I've done right at the end of the day ... [but] when you have no status, that's more important ... it's what defines me. [Emphasis added]
From such statements, it becomes evident that media depictions and the links, no matter how subtle or explicit, between criminal and being undocumented influence youths' identities and that, ultimately, youth feel their identity is defined primarily by their lack of status, not by who they are as an individual.

\section{Stress and Anxiety}

All 47 participants reported experiencing heightened stress and anxiety related to their lack of immigration status. The stress and anxiety stemmed mainly from not being able to control their future, potential disclosure of immigration status, inability to access vital services, precarious employment and financial situations, and lack of information.

\section{Inability to Control One's Future}

All participants reported that much of their stress and anxiety could be attributed to the fact that their precarious immigration status prevents them from being able to control large parts of their lives. As Participant E stated,

Not knowing is stressing. I have a 94 average [in school] and other people [my age] are applying to university, but [I] can't count on that. I don't know if I'm even going to be in Canada next year or tomorrow. If it happens [that I get deported] then I lose everything ... No one ever plans to be deported, it just happens ... so nothing's set and no matter how well you prepare, things might not work out. It's frustrating dealing with that ... there's a lot of just throwing your hands up in the air. I don't know, sometimes it's too much and you feel tense and frustrated ... [and the] stress [of it] all hits hard.

With the immediate and future threat of detention and deportation, an individual's ability to plan and schedule activities is severely constrained and the resulting uncertainty of not knowing where you will be living and what you will be doing in the future are fertile grounds for stress and anxiety. Participant B aptly expresses this:

It seems strange, I know, to others who don't experience [living without status] but a lot of what you do, you do even when you know that everything you do might lead to nothing. You plan your month, education, job, anything ... but you know, you know in the back of your head that all that planning doesn't add up to much if you get deported ... and that's real, [deportation] could happen any moment ... and that's when you feel the panic ... when you know that you don't really know what's going to happen to you. Those are moments when I have this feeling of ... futility. I don't even know, it's so much, too much, stress having to think about [the] future. 
The inability to control or manage the future and basic things such as country of residence, employment, and educational pursuits leads to reports of experiencing heightened levels of stress and trepidation. Because the threat of detention and deportation is endemic to undocumented populations, so too it appears is the stress that comes with uncertainty about the future.

\section{Fear of Disclosure of Immigration Status}

The fear that someone may discover an individual's lack of immigration status was mentioned by all 47 participants as one of the most significant sources of stress and anxiety, and reported as having affected all facets of their lives. Fear of disclosure was the main consideration when contemplating most life decisions, from the most mundane to the most momentous. Participant G explains,

The fear of getting discovered [by immigration authorities] is something you have to worry about. If I go to the grocery store ... ride the bus ... play basketball in the park, I gotta think about it before because my Mom worries a lot. She tells me to be real careful and think if it's safe to go [places]. If someone finds out or asks me for ID, it's over for all of us ... so I think about everything before I go [anywhere].

In addition, many decisions, especially about pursuing friendships and romantic relationships, are affected by this palpable fear that certain situations may leave individuals vulnerable to disclosure of immigration status. Participant L explains,

It's hard to admit it even to myself, but I look back at my relationship with my ex-boyfriend and I feel kinda bad, so guilty. I just couldn't let him in on everything in my life because [lack of status] doesn't affect only me, I have to think of my brothers and sisters and my parents ... I know I wasn't all there ... and should have told him more about my life, but I couldn't. If he knew [about my status], then he could've accidentally told someone who could've told someone and you don't know where that'll go. It's hard to have relationships and be best friends with people when you can't tell them such a big part of your life ... [because your] whole family's safety [is] on the line ... if anyone finds out.

Thus, fear of disclosure of immigration status acted as a social deterrent for the majority of participants when deciding to form or maintain close relationships with potential partners or friends. As Participant D expresses it,

The less people that know, the better. So yeah, sometimes you can't pursue [relationships] but that's how it is. It's better not to get into something than to realize [later that] it's going to get you deported because someone found out.

As such, it becomes increasingly noteworthy that fear of disclosure may lead undocumented youth to refrain from engaging in social relationships and influences all life decisions, whether it be to go to the grocery store or continue being involved with a life partner.

\section{Employment and Financial Stressors}

Undocumented youth are permanently relegated to working within the informal economy where wages and labour conditions are unregulated. They work in dangerous conditions without safety equipment or job protection, since they are not allowed to unionize. The lack of job security is stressful, as Participant $\mathrm{H}$ points out:

I need this job bad, but I don't know how long I'll have it. People [are] always getting fired ... and for three weeks, I haven't gotten paid ... I want to ask [my boss] for it but if I seem pushy, he [might] fire me. It's tiring having school and work ... and then you gotta worry about even seeing the paycheque. Keeping this job is trouble ... but not having it is worse. Everything seems like trouble these days ... I get headaches from thinking too much .... maybe from stress, who knows.

Furthermore, financial compensation in sectors employing undocumented youth is extremely low, and frequently minimum wage standards are not met. Because undocumented youth and their parents work in the informal economy, their socioeconomic status is quite poor. The vast majority of youth in the study reported family income to be less than $\$ 29,000$ a year, effectively placing them in poverty. All 47 participants reported financial problems as a major reason for their high level of stress, since there was often not enough money for food, clothes, rent, and other necessities. The financial burdens are exemplified in Participant $\mathrm{C}$ who states,

There ain't never enough money, never. It's annoying, you just get fed up with the same damn situation, over and over again. You can't even understand the stress I'm feeling all the time. No matter how many hours my parents work or we [siblings] work, it's not enough. My parents get angry and frustrated ... and can I even blame them? I'm tired of it, too.

Given the harsh reality of having to procure a precarious job with little assurance of safety or security, and inadequate compensation, financial and employment factors are prominent stressors and cause for anxiety amongst undocumented youth and their families. 


\section{Protective Factors}

Undocumented youth in the study identified two main protective factors against the stressors associated with not having immigration status: familial support and sense of agency. Though adolescence is typically understood as a period riven with conflictual parent-child relations, 38 youth in the study reported that their families were a significant source of support. In particular, participants consistently mentioned that their families were often the only people they could openly discuss immigration and status problems with and feel safe and understood when expressing their fears and insecurities. In turn, many undocumented adolescents share a close relationship with their parents and/or siblings, and described how not having status required the family unit to be close and united in dealing with these difficulties outside the home. Most adolescents described how their families shared a close bond as a result of having to address status concerns collectively.

Another factor that facilitated a sense of well-being amongst undocumented youth was a personal sense of agency. A sense of agency is an individual's subjective understanding that she exercises some control over her life and can direct her life on the basis of her needs. Although all participants readily acknowledged feelings of helplessness and not being in control of their futures as the result of status barriers, 37 participants also mentioned experiencing a personal sense of agency and feeling they could positively affect their future by working hard, doing well in school, developing networks for work, forging healthy relationships, and working to be their "best" selves. This is particularly important, given that feelings of helplessness and lack of control over immigration status is pervasive in this population. As such, cultivating a personal sense of agency promotes hope and well-being for these adolescents' mental health.

Although much of the results emphasize that undocumented adolescents experience tremendous stressors related to not having status, most of which impede their sense of personal well-being, it is important to note that healthy relationships amongst family members act as an important support system. In addition, fostering a stronger sense of agency amongst undocumented adolescents acts as a protective factor and allows individuals to cope better with their challenges.

\section{Discussion}

The findings of this study indicate that there are significant associations between lack of health security and mental well-being and living as an undocumented youth. Results suggest that being undocumented should be viewed as a psychosocial condition characterized by stress and risk. As a result of the chronic, pervasive uncertainty and fear inherent in living without status, youth in the study exhibited symptoms of anxiety and stress associated with their lack of status. Although all the youth discussed Canada as their home in various ways, their narratives testify to feelings of social exclusion within such settings and Canadian society at large. Because undocumented youth are relegated to the margins of society as "illegals," mental health issues emerge from lack of social inclusion and the inherent stresses associated with living with the constant threat of detention and deportation.

\section{Limitations and Future Research Directions}

Several limitations of the current study need to be addressed. First, in the demographic and personal characteristics of the current sample, there is a selection bias insofar as all participants were recruited from social service and advocacy organizations, and were therefore receiving or had access to services and information. This is a particularly important sampling bias to note, as the vast majority of non-status youth do not have access to services. Consequently, future studies need to account for and creatively recruit non-status youth from non-service sector sites to gauge what the mental health outcomes are for this population where the majority of people will never access social services.

Although this study's findings demonstrate that undocumented youth exhibit symptoms of anxiety and stress, it is unclear whether they would meet diagnostic criteria for clinical disorders, as comprehensive diagnostic evaluations would have to be conducted to determine this. Further, future studies would need to compare rates of anxiety and stress amongst undocumented youth to other similar populations such as refugees or immigrants, to establish whether undocumented youth suffer from higher levels of anxiety, depression, and other mental health issues. This would require quantitative studies in this area, measuring differing rates of mental health issues on numerical scales. Also, despite the fact that this pilot study documented how long youth were living in the country without status, the results showed mixed or inconclusive findings with regard to establishing any association between duration of time living without status and mental health outcomes. However, given that experiences of pervasive stress tend to compound over time if situational stressors are not mitigated or neutralized, this is an important area of study. As such, future studies should explore whether there is an associated relationship between the amount of time an adolescent lives without status and worsening mental health outcomes. Cognizant of the fact that this is an investigational study examining mental well-being and health security in undocumented youth populations in Canada, more research needs to be 
conducted to replicate or repudiate this study's findings before any generalizations can be made.

\section{Policy Directions}

Exclusion and marginalization of undocumented peoples occur within a social and political context that privileges certain individuals' human rights and well-being over those of others. This type of framework creates a false dichotomy of "us" against "them," where the "other" is separated by rights and privileges that are systematically denied them. Undocumented youth and their families should not be forced to live in the shadows of fear and insecurity and should be granted formal immigration status to ensure health security.

Health policies should be devised in order to ensure that immigration status need not be a prerequisite to accessing essential services. Given the pervasive nature of the stress experienced by undocumented individuals, a Don't Ask, Don't Tell (DADT) policy should be adopted and implemented, as it has been in over 30 cities across the United States. This policy would prohibit health and essential service providers from inquiring into individuals' immigration status in order to provide them with a vital service and, in the event that providers inadvertently become aware of an individual's immigration status, they would be barred from disclosing this information to immigration authorities. The DADT policy would reduce the risk and fear of disclosure of immigration status that undocumented youth and their families associate with accessing vital services. By allaying such apprehension and fear, services would be provided on the basis of need, undocumented youth would not be excluded from care, and the result would be improved health security and mental well-being.

Faria Kamal is a fifth-year doctoral student in the School and Clinical Child Psychology Program at the University of Toronto. Her research focuses on migrants and mental health. The author may be reached at faria.kam@gmail.com.

Kyle D. Killian is a family therapist and core faculty in the Marriage and Family Therapy Program at Capella University. He has published articles and book chapters on newcomers and health, trauma and resilience, and self-care and vicarious resilience in helping professionals. The author of Interracial Couples, Intimacy \& Therapy (Columbia University Press, 2013), Dr. Killian is also a blogger at Psychology Today, and has developed measures of traumatic stress, critical thinking, cultural identity, vicarious resilience, and emotional intelligence. The author may be contacted at Kyle.Killian@capella .edu.
Notes

1 Lisa R. Fortuna, "Clinical Issues and Challenges in Treating Undocumented Immigrants," Psychiatric Times, 15 August 2013; Ilene Hyman, "Immigration and Health," Working Paper 01-05 (Ottawa: Health Canada, 2001); Laura Simich, "Hidden Meanings of Health Security: Migration Experiences and Systemic Barriers to Mental Well-Being among Undocumented Migrants in Canada," International Journal of Migration, Heath and Social Care 2, nos. 3-4 (2006): 16-27.

2 Roberto G. Gonzales, Carola Suarez-Orozco, and Maria C. Dedios-Sanguineti, "No Place to Belong: Contextualizing Concepts of Mental Health among Undocumented Immigrant Youth in the United States," American Behavioral Scientist 57, no. 8 (2013): 1174-99; Nazilla Khanlou, "Precarious Immigration Status: Exploring Impacts on Health" (paper presented at the 1oth International Metropolis Conference, Toronto, 17-21 October 2005).

3 Peter Nyers, "Access Not Fear: Non-Status Immigrants and City Services," unpublished, 2006.

4 Steffen Angenendt, "Irregular Migration as an International Problem," Research Paper No. 4 (German Institute for International and Security Affairs, 2008).

5 Carola Suarez-Orozco, Marcelo Suarez-Orozco, and Desiree B. Qin-Hilliard, The New Immigration: An Interdisciplinary Reader (New York: Routledge, 2005); Wayne A. Cornelius, "Interviewing Undocumented Immigrants: Methodological Reflections Based on Fieldwork in Mexico and the U.S.," International Migration Review 16, no. 2 (1982): 378-411.

6 Leo R. Chavez, Shadowed Lives: Undocumented Immigrants in American Society (Fort Worth, Tx: Harcourt Brace Jovanovich College, 1992).

7 Alejandro Portes, The Economic Sociology of Immigration: Essays on Networks, Ethnicity, and Entrepreneurship (New York: Russell Sage Foundation, 1998); Jeffrey S. Passel, The Size and Characteristics of the Unauthorized Migrant Population in the U.S. (Washington, DC: Pew Hispanic Center, 2006).

8 Carola Suarez-Orozco and Marcelo Suarez-Orozco, Transformations: Immigration, Family Life, and Achievement Motivation among Latino Adolescents (Stanford, CA: Stanford University Press, 1995).

9 Ibid., 9.

10 Ibid., 6.

11 Nandita Sharma, "Review of Torillas and Tomatoes: Transmigrant Mexican Harvesters in Canada," Canadian Journal of Sociology 31, no. 1 (2006): 143-4.

12 Michelle Lowry, "Creating Human Insecurity: The National Security Focus in Canada's Immigration System," Refuge 21 (2002): 28-39.

13 Ibid., 17.

14 Michael J. L. Kirby and Wilbert J. Keon, Out of the Shadow at Last: Transforming Mental Health, Mental Illness and 
Addiction Services in Canada (Ottawa: Government of Canada, 2006).

15 Brian D. Gushulak and Douglas W. Macpherson, "Health Issues Associated with the Smuggling and Trafficking of Migrants," Journal of Immigrant Health 2, no. 2 (2000): $67-78$.

16 Laura Simich, "Status and Health Security: An Exploratory Study among Irregular Immigrants in Toronto," Canadian Journal of Public Health 98, no. 5 (2006): 369-73.

17 Jacqueline Oxman-Martinez, Jill Hanley, Lucyna Lach, Nazilla Khanlou, Swarna Weerasinghe, and Vijay Agnew, "Intersection of Canadian Policy Parameters Affecting Women with Precarious Immigration Status: A Baseline for Understanding Barriers to Health," Journal of Immigrant and Minority Health 7, no. 4 (2005): 247-58.

18 Samuel Law, Miles Hutton, and Diana Chan, "Clinical, Social, and Service Use Characteristics of Fuzhounese Undocumented Immigrant Patients," Psychiatric Services 54, no. 7 (2003): 1034-7.

19 Trine Myhrvold, "Undocumentedness, Human Rights and Nurses' Obligations: An Appeal," Discussion Paper No. 1, Oslo University College, 2004.

20 Paul Caulford and Yasmin Vali, "Providing Health Care to Medically Uninsured Immigrants and Refugees," Canadian Medical Association Journal 174 (2006): 1253-4.

21 Ibid., 26.

22 Ibid., 22.

23 Ibid., 1.

24 Ibid., 26.

25 Ibid., 26.

26 Ibid., 5 .

27 Chris R. Smith, David Knights, and Hugh Willmot, WhiteCollar Work: The Non-Manual Labour Process (New York: Macmillan, 1991).

28 Ibid., 12.

29 Portes, Economic Sociology of Immigration, 29.

30 Philip Kretsedemas and Ana Aparicio, Immigrants, Welfare Reform, and the Poverty of Policy (Westport, ст: Praeger, 2004).

31 Ibid., 36.

32 Doreen J. Mattingly, "Working Men and Dependent Wives: Gender, Race, and the Regulation of Migration from Mexico," in Women Transforming Politics: An Alternative Reader, ed. C.J. Cohhen, K.B. Jones, and J.C. Tronto (New York: New York).

33 Ibid., 38.

34 Ibid., 17.

35 Ibid., 8.

36 Ibid.

37 Carola Suarez-Orozco, Hirokazu Yoshikawa, Robert Teranishi, and Marcelo Suarez-Orozco, "Growing Up in the Shadows: The Developmental Implications of Unauthorized Status," Harvard Educational Review 81, no. 3 (2011): 438-72.
38 Hector R. Bird and Madelyn S. Gould, "The Use of Diagnostic Instruments and Global Measures of Functioning in Child Psychiatry Epidemiological Studies," in The Epidemiology of Child and Adolescent Psychopathology, ed. F. Verhulst and H. Koot (Oxford: Oxford University Press, 1995), 86.

39 Bridget O’shea, Matthew Hodes, Gwynneth Down, and John Bramley, "A School Based Mental Health Service for Refugee Children," Clinical Child Psychology and Psychiatry 5, no. 2 (2000): 189-201.

40 Lauren Ellis and Eric Chen, "Negotiating Identity Development among Undocumented Immigrant College Students: A Grounded Theory Study," Journal of Counselling Psychology 60, no. 2 (2013): 251-64.

41 Ibid., 46.

42 Laurence Steinberg and Amanda S. Morris, "Adolescent Development," Journal of Cognitive Education and Psychology 2, no. 1 (2001): 46.

43 Ibid., 43.

44 Adrian Angold, E. Jane Costello, Elizabeth M. Z. Farmer, Barbara J. Burns, and Alaatin Erkanli, "Impaired But Undiagnosed," Journal of the American Academy of Child and Adolescent Psychiatry 38 (1999): 129-37.

45 Ibid., 46.

46 Ibid.

47 Ibid., 43.

48 Ibid.

49 Ibid.

50 Ibid.

51 Ibid.

52 Ibid.

53 Norman K. Denzin and Yvonna S. Lincoln, Introduction: Entering the Field of Qualitative Research (Thousand Oaks, CA: Sage Publications, 1994).

54 Two of the three organizations requested to not be identified in any published materials for concern that publicly acknowledging servicing undocumented peoples may result in the loss of federal or provincial program funding. As such, all organizational identifiers have been removed.

55 Juliet M. Corbin and Anselm Strauss, Basics of Qualitative Research (Newbury Park, CA: Sage Publications, 1998).

56 Dminitris C. Anagnostopoulos, Maria Vlassopoulos, and Helen Lazaratou, "Forced Migration, Adolescence, and Identity Formation," American Journal of Psychoanalysis 66, no. 3 (2006): 225-37.

57 Ibid., 63.

58 Oksana Yakushko, Megan Watson, and Sarah Thompson, "Stress and Coping in the Lives of Recent Immigrants and Refugees: Considerations for Counseling," International Journal for the Advancement of Counselling 30, no. 3 (2008): 167-78. 